Article

\title{
Calibration and Validation of the Cosmic Ray Neutron Rover for Soil Water Mapping within Two South African Land Classes
}

\author{
Thigesh Vather ${ }^{1,2} *$, Colin Everson ${ }^{1,3}$ and Trenton E. Franz ${ }^{4}$ \\ 1 Centre for Water Resource Research, University of KwaZulu-Natal, Pietermaritzburg, \\ Kwa-Zulu Natal 3209, South Africa \\ 2 South African Environmental Observation Network, Pietermaritzburg 3202, South Africa \\ 3 Department of Plant Production and Soil Science, University of Pretoria, Pretoria, Gauteng 0028, South Africa \\ 4 School of Natural Resources, University of Nebraska-Lincoln, Lincoln, NE 68583, USA \\ * Correspondence: thigeshvather@gmail.com; Tel.: +27-83-380-2531
}

Received: 11 May 2019; Accepted: 30 July 2019; Published: 5 August 2019

\begin{abstract}
Knowledge of soil water at a range of spatial scales would further our understanding of the dynamic variable and its influence on numerous hydrological applications. Cosmic ray neutron technology currently consists of the Cosmic Ray Neutron Sensor (CRNS) and the Cosmic Ray Neutron Rover (CRNR). The CRNR is an innovative tool to map surface soil water across the land surface. This research assessed the calibration and validation of the CRNR at two survey sites (hygrophilous grassland and pine forest) within the Vasi area with an area of 72 and 56 ha, respectively. The assessment of the calibrations showed that consistent calibration values $\left(N_{0}\right)$ were obtained for both survey sites. The hygrophilous grassland site had an average $N_{0}$ value of 133.441 counts per minute (cpm) and an average error of $2.034 \mathrm{cpm}$. The pine site had an average $N_{0}$ value of $132.668 \mathrm{cpm}$ and an average error of $0.375 \mathrm{cpm}$ between surveys. The validation of CRNR soil water estimates with interpolated hydro-sense soil water estimates showed that the CRNR can provide spatial estimates of soil water across the landscape. The hydro-sense and CRNR soil water estimates had a $R^{2}$ of 0.439 at the hygrophilous grassland site and 0.793 at the pine site.
\end{abstract}

Keywords: cosmic ray neutron technology; cosmic ray neutron rover; spatial scale; calibration; validation; soil water; hygrophilous grassland; pine forest

\section{Introduction}

Soil water is an important component in the water, carbon and energy cycles, however its dynamics are not well understood due to its spatial and temporal variability [1,2]. Monitoring soil water at a range of spatial scales may improve our understanding of soil water controls on the water, energy and carbon fluxes that occur between the land and atmosphere, which would subsequently lead to the improvement of meteorological forecasting and climate projections [3]. A recent paper found that remote sensing-based estimates of global annual Gross Primary Production were biased low by $15 \%$ due to ignoring soil water effects on photosynthesis [4]. Over the past decade, the importance of soil water has led to an increase in the number and resolution of satellite-based soil water products and the continuous development of fine resolution land-surface models [5].

On one hand, in situ (ground-based) instruments measure soil water at a point-scale and are the conventional approach to measure and monitor soil water. To account for the heterogeneity of soil water, networks were created, by placing several in situ instruments over the measurement area. Although this aimed to overcome the heterogeneity of soil water, the labour, time and cost associated with setting up and maintaining the network greatly constrained this approach, which became infeasible. On the 
other hand, remote sensing is seen as a promising method of soil water estimation, as it overcomes the spatial variability of soil water and has a fairly good temporal observation resolution [6]. However, due to its coarse spatial resolution and shallow measurement depth, its use is limited to regional scale applications [7]. A significant and critical gap still exists in our ability to estimate field scale ( $\sim .1$ to $10 \mathrm{ha}$ ) root zone $(0-1 \mathrm{~m})$ soil water [8].

Soil water instruments have advanced significantly, however intermediate scale measurement gaps (between point-based measurements and satellite-based estimates) remain $[9,10]$. The method of cosmic ray neutron technology for soil water estimation was first introduced to the environmental science community by Zreda, et al. [11]. Cosmic ray neutron technology currently consists of the Cosmic Ray Neutron Sensor (CRNS), which is a fixed (stationary) in situ (ground-based) instrument that is used for soil water monitoring and the Cosmic Ray Neutron Rover (CRNR), which is an instrument that is placed in a vehicle and driven around a survey area, to map soil water.

Cosmic ray neutron technology is a promising technique for soil water estimation, as it is capable of estimating soil water at an intermediate scale, providing an unprecedented scale of observation and has the potential to fill the measurement gap between in situ point measurements and coarse-scaled satellite-based remote sensing soil water estimates. The CRNS was the first instrument developed and implemented, therefore most of the research on cosmic ray neutron technology has focused on and used the CRNS. The CRNR was developed to conduct large-scale soil water surveys, as a result of the CRNS's capabilities [12]. The capability to estimate the area-averaged soil water content over a large volume remains a valuable advantage of the cosmic ray neutron method [13]. However, the method does require calibration and corrections, in order to provide reliable and accurate soil water estimates. Due to the novelty of the CRNR and the fact that there are only a handful of CRNR's worldwide, there is very limited research conducted on this instrument.

The following known studies have been conducted using the CRNR. Desilets, et al. [14] first used the CRNR to monitor transects across Hawaii, Chrisman and Zreda [15] first described the practical applications, as well as the challenges in a study that used the CRNR to monitor entire basins in Southern Arizona, Dong, et al. [12] used the CRNR to compare against remote sensing soil water products in central Oklahoma and found that the CRNR provides a valuable technique for the calibration and validation of microwave remote sensing products, Franz, et al. [16] used the CRNR to monitor 140 agricultural fields in Nebraska, Schrön, et al. [17] investigated the effects that roads have on the CRNR, Fersch, et al. [18] used the CRNR and other complementary methods to determine soil water within a $55 \mathrm{~km}^{2}$ Alpine foothill river catchment in Southern Germany and Finkenbiner, et al. [19] and Gibson and Franz [20] used the CRNR to map soil water within agricultural fields in Nebraska. These prior studies have generally used the CRNR to estimate soil water over large spatial areas, which are comparable with global satellite-based soil water.

The CRNR has yet to be investigated on the African continent. This research paper focuses on the calibration and validation of the CRNR at the Vasi site, at spatial scales smaller than those investigated in past research. This research seeks to bring new insight into the use of the CRNR, to serve as a basis for future theoretical and practical applications of the promising new method.

\section{Methodology}

\subsection{Study Site}

The Vasi area falls within the Maputuland Coastal Plain, which is located in the North-eastern part of KwaZulu-Natal, in South Africa (Figure 1) and hosts an array of wetlands, which provide valuable ecosystem services [21]. There are a variety of land uses/vegetation throughout the area, which include densely forested areas, scattered areas of dry grasslands, hygrophilous grasslands and thicket. The area is a groundwater-driven system and is characterised by its sandy soils. This results in the soil surface having high infiltration and relatively low water retention. The area has a subtropical climate with hot and humid summers and mild winters [21]. The mean annual precipitation ranges 
between 750 and $800 \mathrm{~mm}$, of which $80 \%$ occurs in the summer months (November to March). As a result, there is a distinct dry season, which occurs from May to August.
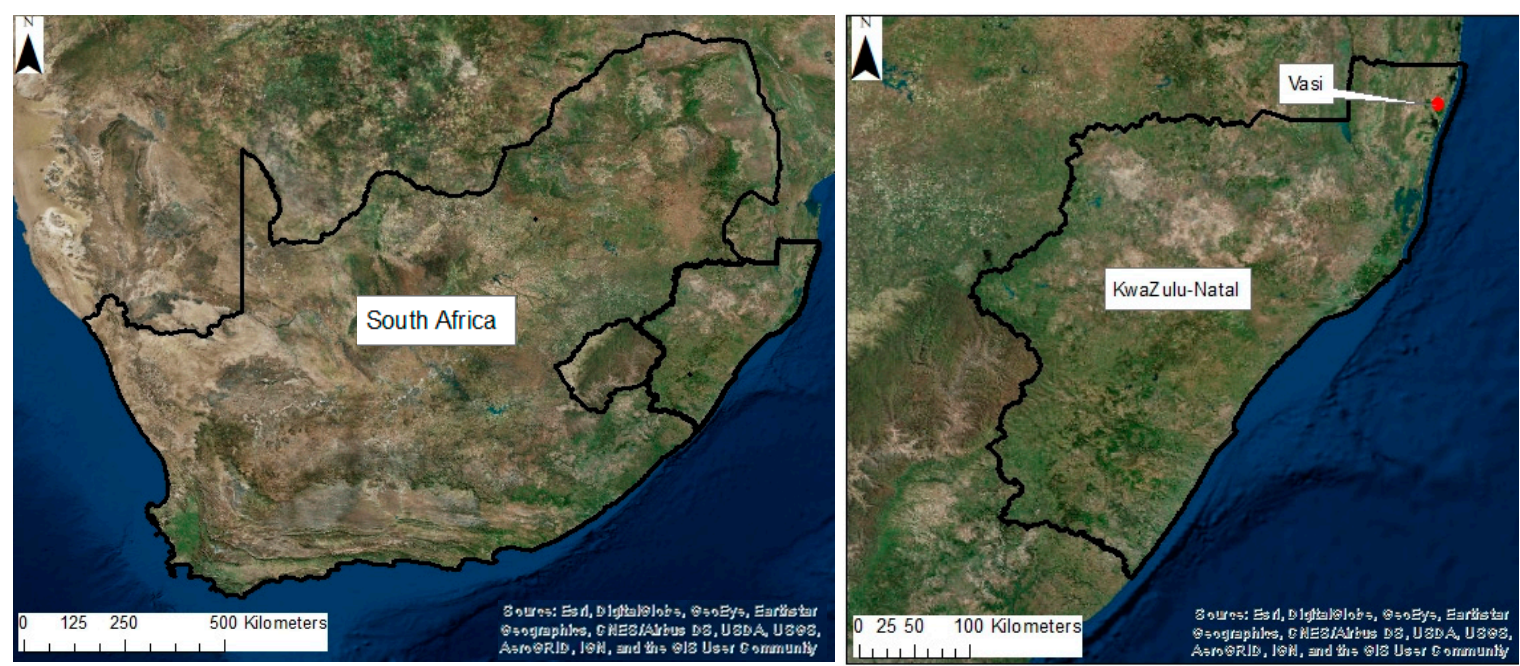

Figure 1. Vasi site within KwaZulu-Natal in South Africa.

The area is of great importance and interest, as Lake Sibiya, which is South Africa's largest freshwater lake, has exhibited a decline in lake level over the past decade, which is a result of the decreasing groundwater table of the region. This change can be attributed to the impacts of land use change, water abstractions and climate change. Therefore, over the past decade, there has been a decrease in wetlands and a subsequent increase in grassland distribution in the area. A noticeable land use change within the region has been the increase in forestry. This has resulted in an increase in the water use of the area, as forestry generally uses more water than the indigenous grassland vegetation, which has led to the decline of the region's water resources and the subsequent decrease in the water table.

Within the Vasi area, two survey sites were selected (Figure 2). The criteria for selecting the sites were that the two sites had to differ in landcover, both sites had to be accessible by vehicle and the sites had to be substantially large. For these reasons, a hygrophilous grassland site and a pine forest stand were selected as the survey areas, with the advantage of the sites being near one another.

The hygrophilous grassland study site was a large open area, situated adjacent to a peatland. The mean elevation of the site was $53 \mathrm{~m}$ and the site coordinates were -27.1862 (latitude) and 32.7081 (longitude). The site was vegetated with mostly hygrophilous grassland, however there were smaller areas of dense bush (thicket), which were mainly found in the depressions that were commonly located towards the centre of the survey area. The dimensions of the site were roughly $300 \mathrm{~m} \times 2400 \mathrm{~m}$ with an area of 72 ha. The hygrophilous grassland site was previously a wetland, which subsequently dried up, as the water table dropped.

The pine forest study site was a stand of seven-year-old Pinus elliotii, with tree heights not exceeding ten metres and tree spacings wide enough (roughly $3 \mathrm{~m}$ ) for a vehicle to manoeuvre throughout the survey area. The mean elevation of the site was $73 \mathrm{~m}$. The site coordinates were 27.1928 (latitude) and 32.7158 (longitude). The pine site had an area of grassland and woodland towards the centre of the site. The dimensions of the site were roughly $660 \mathrm{~m} \times 850 \mathrm{~m}$ with an area of 56 ha. 

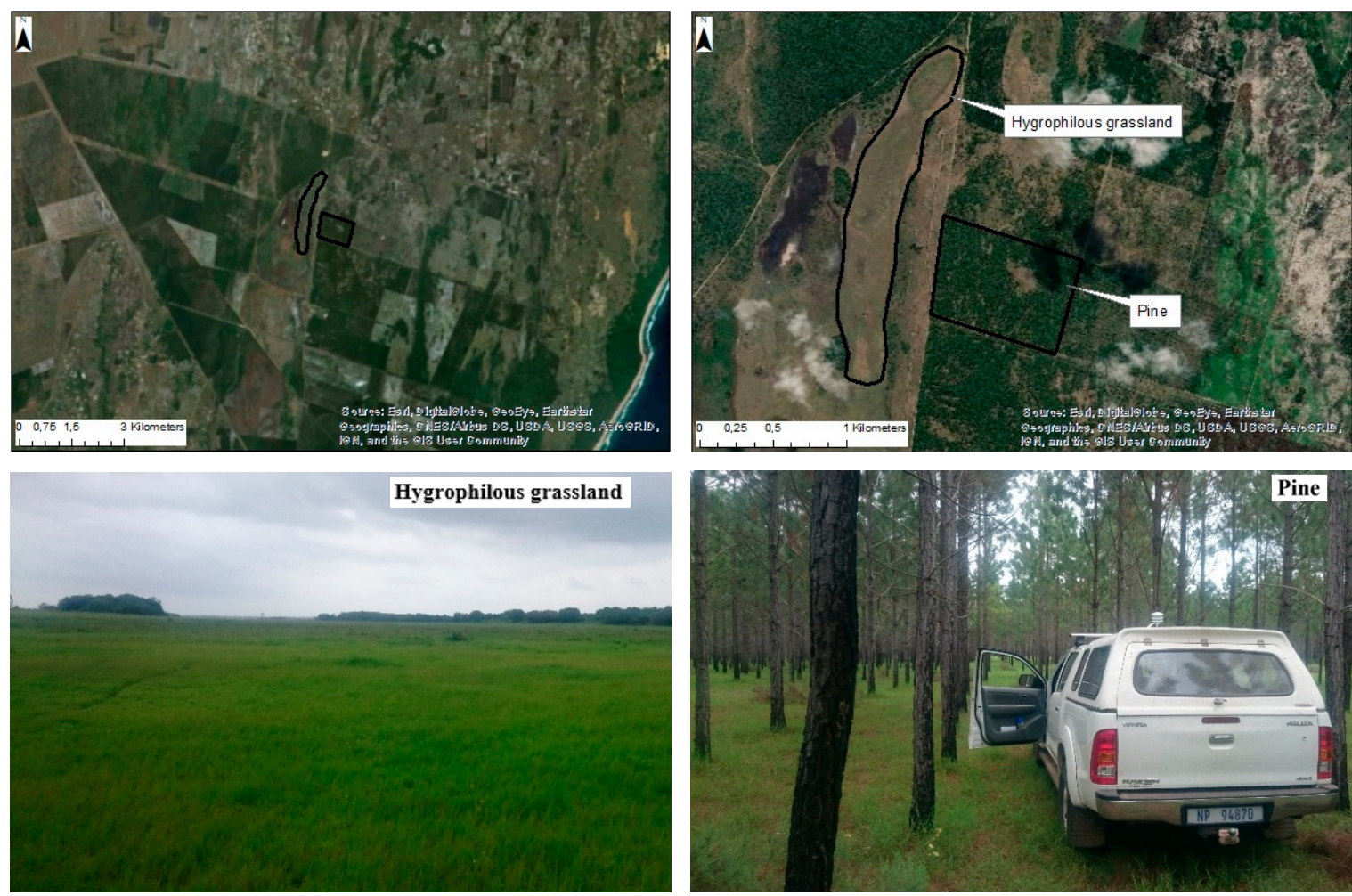

Figure 2. Hygrophilous grassland and pine survey sites.

\subsection{Cosmic Ray Neutron Method}

Cosmic ray neutron technology is a novel approach to soil water estimation. Cosmic ray neutrons are high-energy subatomic particles, which originate in outer space [12]. These particles penetrate through the Earth's magnetic field and into the atmosphere [22]. Cosmic ray neutrons interact with atmospheric nuclei, which results in a cascade of secondary cosmic rays (epithermal neutrons), which move towards the land surface and encounter a denser mass when they reach the soil [23]. Most of the epithermal neutrons are absorbed by collisions with nuclei present in the soil, however some neutrons are scattered above the soil surface. The amount of epithermal neutrons above the soil depends on the hydrogen content of the soil, as hydrogen is the most effective element in the absorption and thermalization of epithermal neutrons [23]. Therefore, there is an inverse relationship between the above-ground neutron intensity and the hydrogen content [14]. The cosmic ray neutron method operates by measuring and monitoring the neutron intensity above the land surface. There are numerous sources of hydrogen within the land-surface. Soil water is a major source of hydrogen at the land-surface and can be isolated from the neutron intensity, by accounting for the other hydrogen sources and correcting the observed epithermal neutron intensity for changes in high-energy neutron intensity, air pressure, and air humidity [9].

\subsection{Cosmic Ray Neutron Rover System}

The CRNR is an innovative and promising approach to map soil water with a ground-based vehicle [17]. The CRNR uses the same detection principle as the stationary CRNS but deploys multiple and larger neutron detectors in order to obtain higher count rates at shorter time intervals [17]. The stationary CRNS integrates neutron counts over a long time period to produce a small uncertainty [15]. The CRNR uses a short counting interval, which is fundamental for the instrument to capture fine spatial resolutions while surveying [24]. There is a trade-off between the counting interval and the precision of the instrument. As the counting interval decreases, the neutron count decreases, which results in a decrease in the instruments precision to estimate soil water. Therefore, 
the more neutron tubes the system possesses, the higher the neutron counts, which results in more precise measurements of soil water [15].

The CRNR system used in this study is based around a set of six custom made ${ }^{3} \mathrm{He}$-filled tube capsules (thermal neutron detectors) designed and supplied by Hydroinnova LLC (Albuquerque, NM, USA). These tubes are shielded by $2.54 \mathrm{~cm}$ thick polyethylene and housed in a weatherproof detector module. The polyethylene not only prevents most thermal neutrons in the natural radiation environment from entering the detector, but also slows down the epithermal neutrons so that they can be measured $[25,26]$. The system also consists of neutron pulse modules connected to the counters that monitor the neutron counts, a datalogger that records the neutron counts, a barometric pressure sensor, a GPS receiver, a temperature and relative humidity sensor, which are mounted outside the vehicle [12]. It is also worth noting that additional meteorological sensors can be added to the control module (for future use).

Since the CRNR uses the same technology as the fixed CRNS, it has the same horizontal footprint and effective measurement depth. The horizontal footprint radius is the area containing $86 \%$ of the detected neutrons. This radius was initially estimated to be $330 \mathrm{~m}$ at sea level by Desilets and Zreda [27], however a more recent study conducted by Köhli, et al. [13] found that the radius is between 130 and $240 \mathrm{~m}$ at sea level. The radius is inversely proportional to air density and therefore the radius increases with elevation [28]. The swath width of the CRNR varies slightly but can be reasonably assumed to be near constant [15]. Therefore, the footprint of the CRNR is the swath with its width equal to the footprint of the CRNS, and its length equal to the distance travelled during the counting interval. The survey sites are between 50 and $80 \mathrm{~m}$ above sea level. This results in a measurement footprint of $\approx 200 \mathrm{~m}$, using the equations from Desilets and Zreda [27]. The effective measurement depth ranges between 0.12 and $0.72 \mathrm{~m}$ and varies with the soil water content $[7,13,29]$. There is an inverse relationship between the effective measurement depth and the soil water content, such that the effective measurement depth decreases as the soil water content increases. However, this inverse relationship is not linear. We also note that the observed dynamic range of soil water content at a site will further constrain the depth range of the CRNR. The CRNR has several potential applications that extend through several disciplines. The CRNR can be used as a tool to delineate riparian areas and wetlands, as it provides spatial estimates of soil water across the land surface at a range of scales. This application would allow for better water management practices, especially in complex ecosystems. The CRNR provides the ability to estimate soil water at a range of spatial scales. This provides further opportunities in commercial activities. One such activity would be precision agriculture in which the CRNR can be mounted to existing autonomous farm equipment and/or rotating infrastructure, which would offer interesting sensing possibilities, as well as having the advantage of being cost effective [30]. Agriculture uses a large amount of the water resource, therefore any reduction in the use of water will greatly benefit the other water users. The CRNR can provide soil water data at relevant scales for the validation and calibration of satellite-based and modelled soil water estimates [31]. The CRNR can provide soil water data at a range of spatial scales, which could be used to better understand soil water dynamics.

\subsection{Cosmic Ray Neutron Rover Surveys}

The CRNR was placed in the bed of the vehicle and driven within the two sites in a pre-defined pattern, depending on the shape and size of the site. The neutrons are most sensitive to hydrogen (factor of 25+ over other elements) [9,11], which results in the vehicle appearing almost transparent [17]. In order to assign a spatial location to each observation, the midpoint between successive CRNR locations was taken [16]. The temperature, relative humidity and barometric pressure sensors were mounted to the vehicle's roof rack (note that these sensors must be placed outside the vehicle). Although the CRNR system has an internal GPS, the external GPS sensor was also connected, as it has a higher positional accuracy. A laptop was connected to the CRNR and used to monitor the measurements in real-time, which is a good way of making sure all the sensors have been connected 
correctly and that the system is functioning. The neutron counts were totalled and recorded each minute. The GPS coordinates, temperature, relative humidity and pressure were also recorded at the end of each one-minute interval.

Along with each CRNR survey, a $0.20 \mathrm{~m}$ hydro-sense soil water probe, which is a portable time domain reflectance probe was used to obtain volumetric water content measurements throughout the survey area. The hydro-sense probe was inserted vertically into the soil at each sample point and provided the soil water content (in real-time), which was averaged over the $0.20 \mathrm{~m}$ rod depth of the sensor. The measurement volume of the hydro-sense instrument is the rod length and extends out radially $3 \mathrm{~cm}$ from the rod, which results in an elliptical footprint shape, with a measurement volume of $1100 \mathrm{~cm}^{3}$. The hydro-sense uses the soil physical property dielectric permittivity to estimate the volumetric water content $(\%)$. The volumetric soil water data from the hydro-sense probe was required to first calibrate the CRNR (survey one and two) data and then used to validate the CRNR (survey three and four) soil water estimates. Therefore, the hydro-sense soil water surveys were intensive and generally aimed to cover the survey area on a $100 \times 100 \mathrm{~m}$ sample grid.

In total, eight CRNR surveys were conducted in the Vasi area. Four surveys were conducted at the hygrophilous grassland site and four surveys were conducted at the pine stand site. The hygrophilous grassland survey generally took six hours to complete, whilst the pine forest survey generally took four hours to complete. The survey dates are shown in Table 1. Due to the time required to carry out the surveys, the hygrophilous grassland and pine surveys for each survey trip (one to four) were carried out on consecutive days (weather permitting). The CRNR data and hydro-sense soil water data can be found in the Supplementary Material.

Table 1. Survey dates.

\begin{tabular}{ccc}
\hline Survey & Hygrophilous Grassland & Pine \\
\hline One & 23 November 2016 & 24 November 2016 \\
Two & 15 February 2017 & 17 February 2017 \\
Three & 30 May 2017 & 31 May 2017 \\
Four & 29 January 2018 & 30 January 2018 \\
\hline
\end{tabular}

When the surveys were carried out, the vehicle was driven on the natural vegetation of the survey area. There were "dirt" roads leading to and adjacent to the survey areas, however these were avoided when carrying out the survey. This was an advantage of surveying these two sites, as the presence of roads have a biasing influence on the surveys and need to be properly accounted for. The effects of roads on CRNR and the relevant corrections are detailed in the study by Schrön, et al. [17].

The CRNR survey path and the hydro-sense soil water points for the hygrophilous grassland site are illustrated in Figure 3. Each point in the CRNR path indicates where a one-minute neutron count was measured. The survey points show that all the surveys carried out over the hygrophilous grassland covered the same area, with some variations in the survey path followed. Survey one covered the smallest area, as only once the survey was conducted, it was apparent that the survey area could be increased, which was then undertaken in the subsequent surveys (surveys two, three and four). The hygrophilous grassland site had landscape depressions towards the centre of the site. These depressions were not driven on, but were navigated around, as the vehicle would get stuck in these depression zones. The hydro-sense soil water points were taken along the CRNR survey path. In some instances, hydro-sense points were taken in the depression zones, as these were accessible by foot.

The CRNR path and hydro-sense soil water points for the pine site surveys are illustrated in Figure 4. Each point in the CRNR path indicates where a one-minute neutron count was measured. Once again, the same survey area is covered with variations in the survey path followed. The pine site was a good site to survey, as the entire pine stand was accessible, however the inconsistencies in the tree spacing were a challenge to manoeuvre the vehicle in certain parts of the pine forest. 

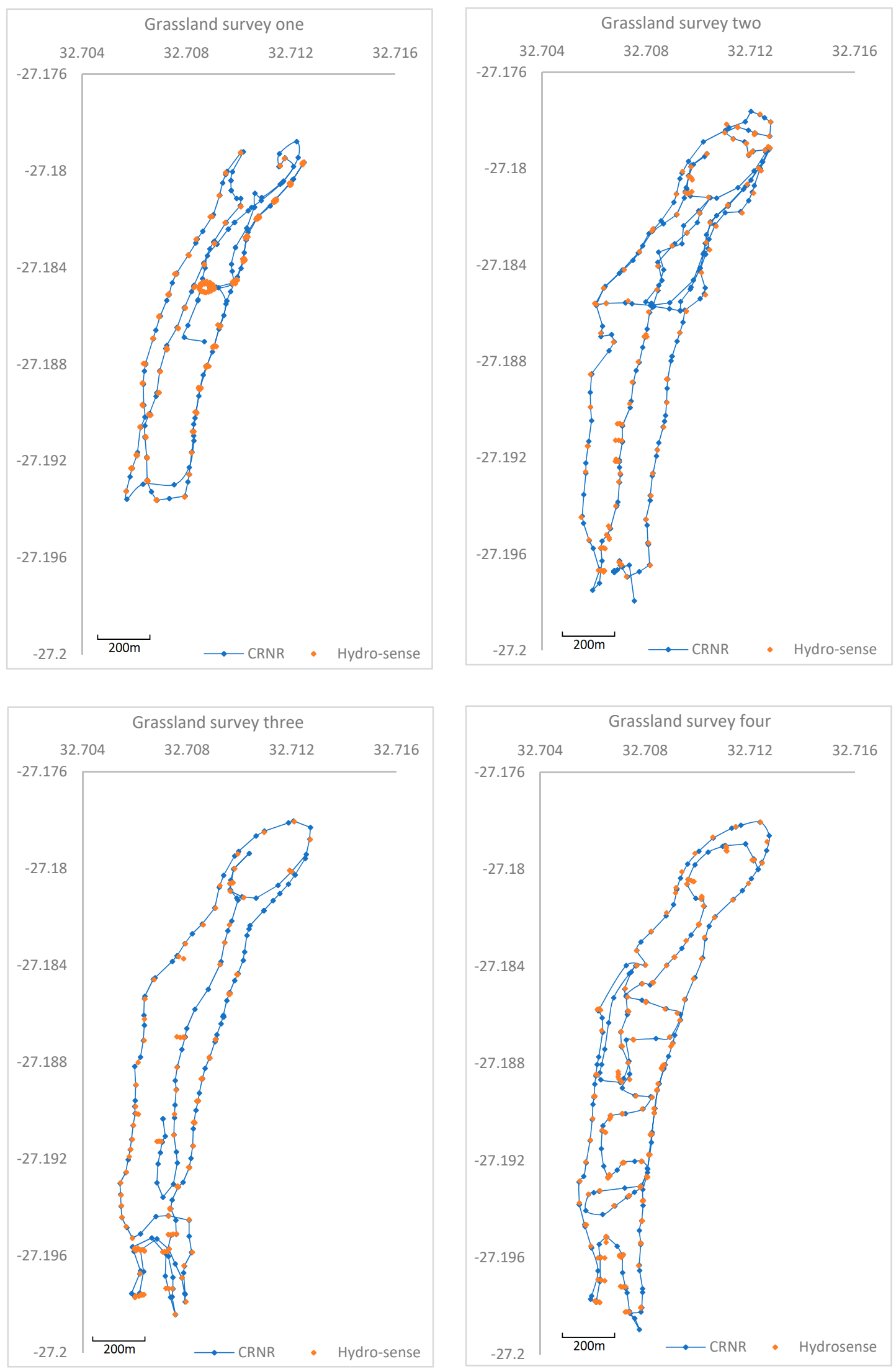

Figure 3. Cosmic Ray Neutron Rover (CRNR) paths and hydro-sense points of hygrophilous grassland surveys. 


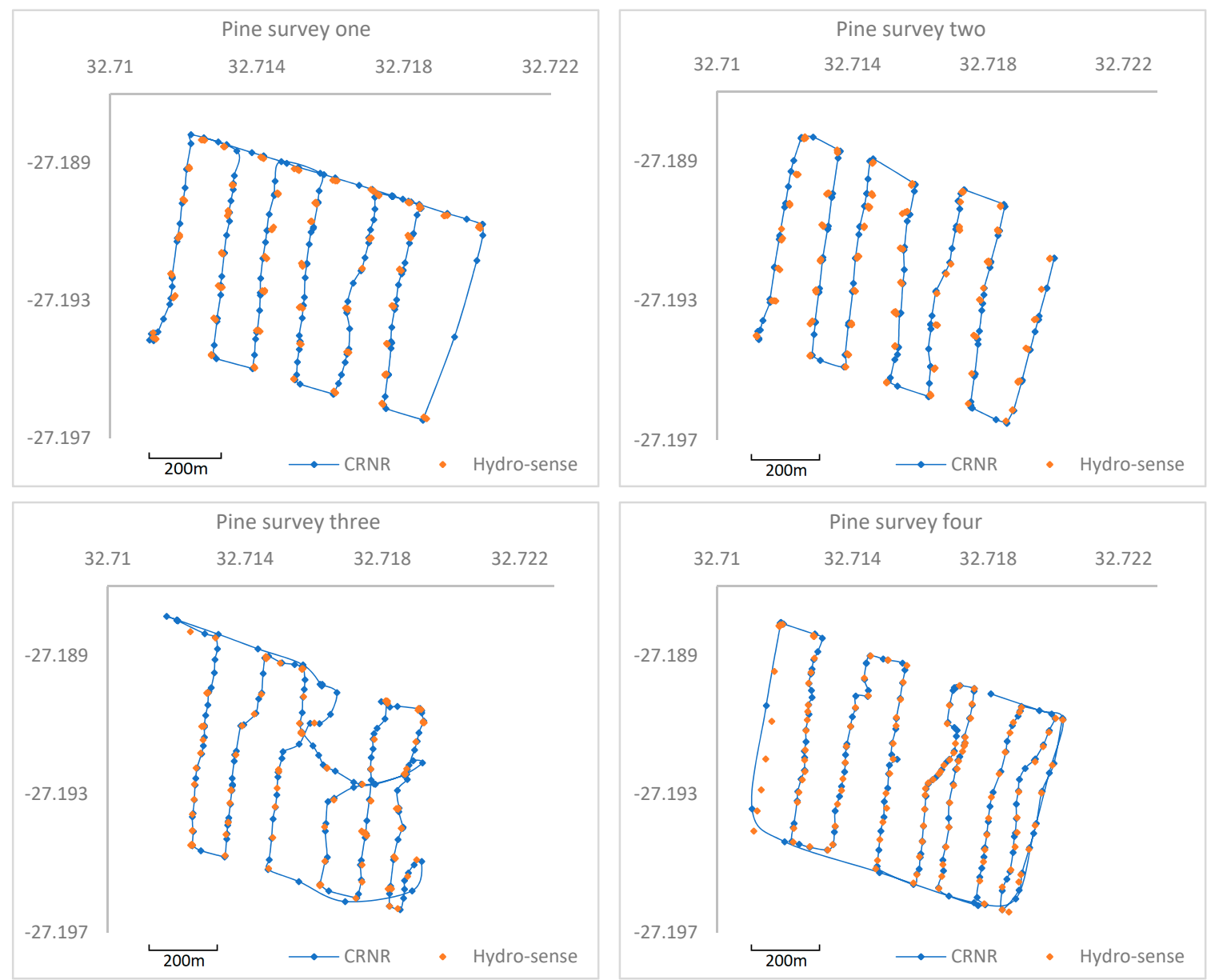

Figure 4. CRNR paths and hydro-sense points of pine stand surveys.

For both survey sites, the outer survey path of the CRNR generally forms the outline for the site. Although the CRNR measures beyond this outline, by as much as the radius of the CRNR measurement footprint, the uncertainty surrounding soil water dynamics results in the avoidance of the extrapolation of both the hydro-sense and CRNR data beyond this boundary.

When carrying out the surveys at both the hygrophilous grassland and pine stand sites, the vegetation was not completely homogenous throughout the survey area. The hygrophilous grassland site had areas of thicket and open bush, which were commonly found in the depressions of the landscape. The Pine forest stand had an area of bracken in amongst the north-eastern part of the pine site, as well as small areas of dense bush along the western and southern boarders of the survey site. These changes in vegetation can be seen in the satellite imagery of the survey areas, as well as in the South African landcover map and/or remote sensing images of vegetation parameters, such as the Normalized Difference Vegetation Index (NDVI), which was obtained on 19 January 2017 by processing Landsat 8 (Operational Land Imager and Thermal Infrared Sensor) data in the Integrated Land and Water Information System (ILWIS) software (Figure 5). The satellite imagery, landcover maps and NDVI maps correlate well with each other, as they all pick up the changes in vegetation throughout the land surface. 

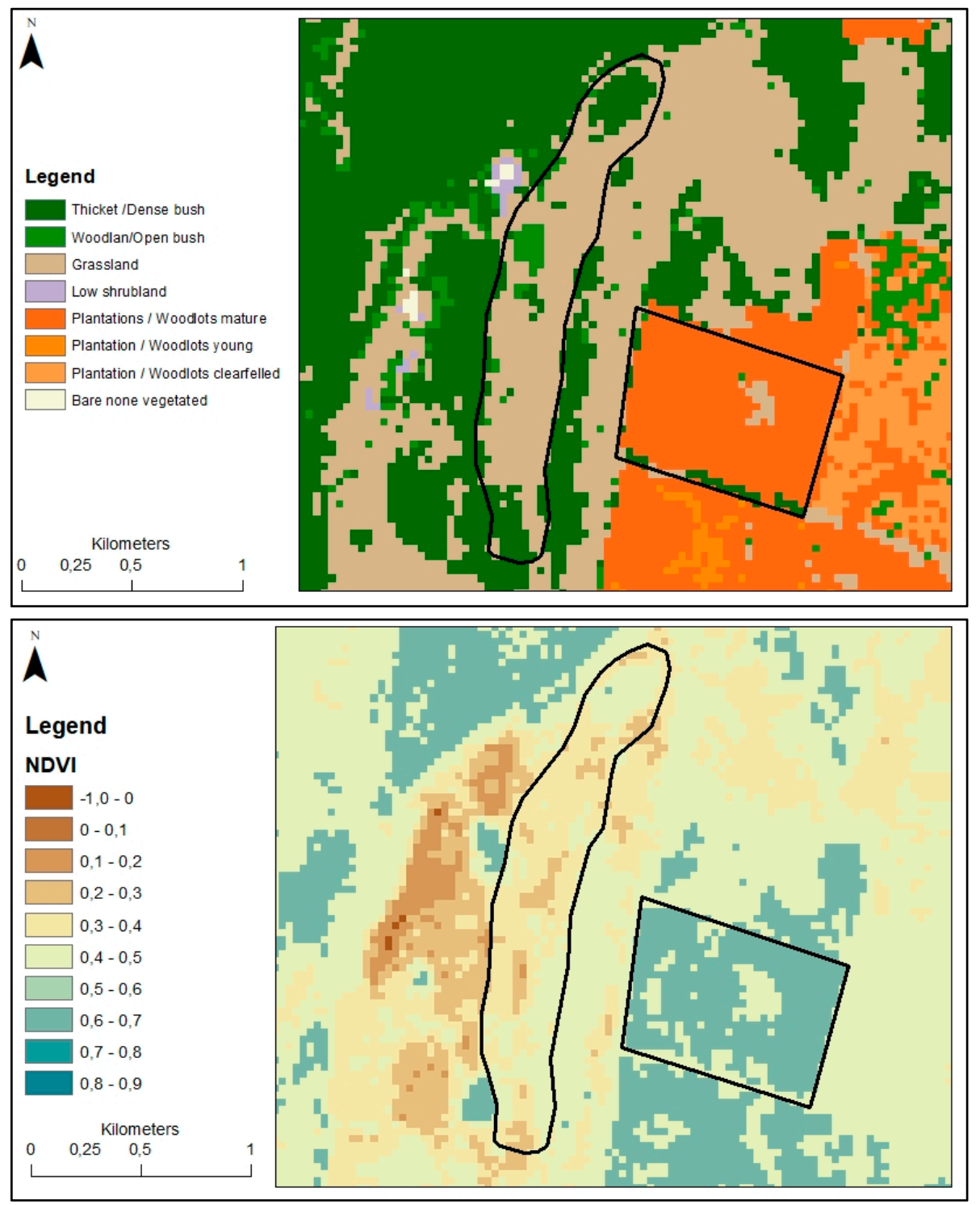

Figure 5. Landcover and Normalized Difference Vegetation Index (NDVI) map of survey sites.

\subsection{Neutron Correction Factors}

The measured neutron count, obtained from the CRNR survey, depends on the total hydrogen in the instruments measurement volume, as well as external factors [9]. In order to isolate the soil water signal, the other sources of hydrogen, as well as the external factors, which affect the neutron signal need to be accounted for [15]. The other hydrogen sources include water in above-ground and below-ground biomass, lattice water, atmospheric water vapour and water in soil organic carbon. The external factors include incoming cosmic ray neutrons and barometric pressure $[32,33]$.

It is first necessary to correct the neutron count for atmospheric water vapour, barometric pressure and incoming cosmic ray neutrons. These factors exhibit temporal variation and therefore need to be accounted for at a similar temporal interval, as the CRNR (one-minute). The formulations for handling these corrections have been investigated and developed in past research.

The atmospheric water vapour correction was proposed by Rosolem, et al. [34], who used a combination of neutron transport modelling and measurement data to develop a correction factor. The correction alters the measured neutron intensity to that of a reference atmospheric water content:

$$
F_{w v}=1+0.0054\left(P_{v o}-P_{v o}^{r e f}\right)
$$


where $P_{v o}$ is the specified absolute humidity and $P_{v o}{ }^{r e f}$ is the reference absolute humidity.

The cosmic ray neutron intensity is sensitive to the elevation, which is defined as an exponential relationship with barometric pressure. The correction for atmospheric pressure $\left(F_{p}\right)[9,11]$.

$$
F_{p}=\exp \left(\frac{P_{0}-P}{L}\right)
$$

where $P_{0}$ is the reference pressure, $P$ is the pressure at the specific site and $L$ is the mass attenuation length for high-energy (mbar or $\mathrm{g} \mathrm{cm}^{-2}$ ). $L$ varies between $128 \mathrm{~g} \mathrm{~cm}^{-2}$ (at high latitudes) and $142 \mathrm{~g} \mathrm{~cm}^{-2}$ (at the equator) [9].

The CRNS data also needs to be corrected for incoming cosmic ray neutron variations. The flux of cosmic ray neutrons that reach the earth's surface is influenced by the spatial and temporal variations in the intensity of incoming primary cosmic ray particles. These high-energy fluxes are not affected by the soil water and are measured at neutron monitoring stations, which are located across the world [35]. An intensity correction factor $\left(F_{i}\right)$ is used to account for variations in incoming neutron flux, thereby, fluctuations in the incoming neutron flux are removed by normalising the source intensity to a fixed point in time [35].

$$
F_{i}=\frac{I_{m}}{I_{r e f}}
$$

where $I_{m}$ is the monitored neutron counting rate at the selected time and $I_{r e f}$ is the neutron counting rate for the same station, at a fixed point in time. The $I_{\text {ref }}$ date used by the COSMOS network is 1 May 2011 [35]. The incoming neutron data used in this study is from the Jungfraujoch monitoring station, which was accessed through the Neutron Monitor Database (www.nmdb.eu).

The corrected neutron counts $(N)$ are then determined using the correction factors and the raw neutron counts $\left(N^{\prime}\right)$ :

$$
N=N^{\prime} \times F_{w v} \times F_{p} \times F_{i}
$$

Once the neutron count has been corrected for variations in high-energy neutron intensity, barometric pressure and atmospheric water vapour, its variability is then just a function of the main hydrogen sources/stocks (pore water, lattice water, water in soil organic carbon, vegetation), which will be accounted for in the calibration [15]. Corrected neutron count maps of the survey areas were created for each survey by Inverse Distance Weighting (IDW) interpolation (power parameter of 2 and variable search radius) of the CRNR corrected neutron (one-minute) data. These maps were processed on a $50 \mathrm{~m}$ spatial grid.

\subsection{Calibration}

The calibration of the CRNS is a standardized procedure, as the probe is fixed. The calibration of the CRNR is a significant challenge, as the heterogeneity of soil and vegetation characteristics across the landscape is problematic [36]. A major limitation of the CRNR for soil water estimation is that the calibration and corrections need to be conducted both temporally and spatially, which is a difficult limitation to overcome, as the various factors change throughout the landscape and need to be accounted for in order to provide reliable soil water estimates. This is a significant challenge and limits the full potential of the CRNR. A recent study by Avery, et al. [36], aimed to develop and test the accuracy of using globally available datasets (clay weight percentage, soil bulk density and soil organic carbon) to support the CRNR.

In order to convert the corrected neutron counts to soil water, the standard approach presented by Desilets, et al. [14] is used. The moderated neutron counts were first used to obtain the $N_{0}$-calibration value, which is the neutron count over dry soil, under the same reference conditions:

$$
N_{0}=\frac{N}{\frac{0.0808}{\theta t+0.115}+0.372}
$$


where $N$ is the corrected neutron counts, $\theta t$ is the total water $\left(\mathrm{g} \mathrm{g}^{-1}\right)$, which consists of the gravimetric soil water $\left(\theta_{p}\right)$, lattice water $\left(\theta_{l w}\right)$ and soil organic carbon $\left(\theta_{s o c}\right)$ all in units of $\mathrm{g} \mathrm{g}^{-1}$. The volumetric soil water $\left(\theta_{p}^{*} p b / p w\right)$, in units of $\mathrm{cm}^{3} \mathrm{~cm}^{-3}$, used in the equation is the hydro-sense soil water map, where $p b$ is the dry soil bulk density and $p w$ is the density of water assumed to be $1 \mathrm{~g} \mathrm{~cm}^{-3}$. The hydro-sense soil water maps were created for each survey (one, two, three and four), by interpolating the hydro-sense soil water data using IDW (power parameter of 2 and variable search radius). The following assumption was made, when using the hydro-sense, which measures soil water at a depth of $0-20 \mathrm{~cm}$, to calibrate the CRNR. During the hydro-sense calibration, the soil water profile is uniform or follows hydrostatic conditions. A more hydrostatic profile is expected, as the calibrations were undertaken several days after any rainfall and the water table is sufficiently deep for these sandy soils. The calibration function used in this study may not hold for times without a hydrostatic profile.

The output of the equation is a map of the $N_{0}$ values of the surveyed area from which the average $N_{0}$ value is determined. This results in a single $N_{0}$ value being obtained for the entire survey area.

This average $N_{0}$ value was then used in the rearranged calibration equation to determine the estimated CRNR soil water map. The calibration parameter $N_{0}$ remains constant in time unless there is a significant vegetation change between surveys.

$$
\theta p \times p b=\left(\left(\frac{0.0808}{\frac{N}{N_{0}}-0.372}-0.115\right)-\left(\theta_{l w}+\theta_{s o c}\right)\right) p b
$$

The CRNR and hydro-sense soil water maps were output as volumetric water content percentage (VWC \%). This unit (VWC \%) was used for all soil water survey maps, performance metrics and scatterplots.

Moreover, there are a few general assumptions made in the method when correcting and calibrating the CRNR; (i) the CRNR has minimal directional bias during the collection of data throughout the survey area, (ii) the calibration sites are adequate to account for the heterogeneity of the surface properties, which include lattice water, soil organic carbon and vegetation, and (iii) there are sufficient sampling points within the survey area to create a representative soil water map [15]. Although the sites vary in vegetation, the change in hydrogen with changing vegetation is a small fraction, when compared to the hydrogen present in the soil water and therefore, in this instance, this vegetation change is negligible.

The general limitation of the CRNR is to account for the spatial heterogeneity of certain soil properties throughout the survey area, which is a very challenging task [17]. The required soil properties are the soil bulk density, lattice water and water contained in soil organic carbon. The lattice water was not determined in a lab, but was estimated using the clay percentage and the equation presented in [5], which relates the clay percentage to the lattice water. The clay percentage of the area was obtained from the globally available soil taxonomy and soil texture data set. Previous studies on cosmic ray neutron technology have related the clay percentage to the lattice water, as the determination of lattice water uses equipment that is not commonly found in standard soil science labs. The water contained in soil organic carbon was obtained from the global datasets. The bulk density of the two survey areas were obtained by taking several soil cores throughout the survey area and determining a representative bulk density value. The lattice water was calculated to be $0.009 \mathrm{~g} \mathrm{~g}^{-1}$, at both sites. The water in soil organic carbon was determined to be $0.01 \mathrm{~g} \mathrm{~g}^{-1}$ (hygrophilous grassland) and $0.02 \mathrm{~g} \mathrm{~g}^{-1}$ (pine stand). The bulk density was $1.5 \mathrm{~g} \mathrm{~cm}^{-3}$ (hygrophilous grassland) and $1.4 \mathrm{~g} \mathrm{~cm}^{-3}$ (pine stand).

\section{Results}

The results section is structured as follows. First, the calibration procedure is carried out to determine the $N_{0}$ values of survey one and two at the hygrophilous grassland and pine forest sites. Next, the average $N_{0}$ values obtained from the calibration (surveys one and two), are used to produce the CRNR soil water maps for surveys three and four. The CRNR soil water maps produced (surveys 
three and four), will be validated against the hydro-sense soil water measurements (surveys three and four), which were obtained during each corresponding survey. The validation is composed of a visual observation on the CRNR's ability to estimate spatial soil water, followed by a more statistical validation approach.

\subsection{Calibration Assessment}

The calibration of the CRNR is challenging, as it requires an independent and representative soil water map of the survey area. In order to provide reliable and accurate estimates of soil water, the CRNR needs to be calibrated correctly and the necessary corrections need to be conducted. For the purpose of this research, calibration values $\left(N_{0}\right)$ were determined for survey one and two using Equation (5) (Table 2). These $N_{0}$ values were determined as the average $N_{0}$ value throughout the survey area for that specific survey. The calibration curves of the hygrophilous grassland site (red) and pine site (blue) are illustrated in Figure 6. These curves illustrate the relationship between the neutron count (cpm) and VWC (\%) at the hygrophilous grassland and pine sites. The hygrophilous grassland site has $N_{0}$ values of 131.406 counts per minute (cpm) (survey one) and $135.475 \mathrm{cpm}$ (survey two), with an average $N_{0}$ value of $133.441 \mathrm{cpm}$. The pine site has $N_{0}$ values of 133.043 (survey one) and $132.293 \mathrm{cpm}$, with an average $N_{0}$ value of $133.668 \mathrm{cpm}$. Overall, there is minimal variance in the values, considering all the confounding factors required to determine the $N_{0}$ value, such as the corrected neutron counts and the hydro-sense soil water measurements. The average error of the hygrophilous grassland ranged from $-2.034 \mathrm{cpm}$ (survey one) to $2.034 \mathrm{cpm}$ (survey two) and the average error at the pine site ranged from $0.375 \mathrm{cpm}$ (survey one) to $-0.375 \mathrm{cpm}$ (survey two). Therefore, the average error of each value is low when each survey $N_{0}$ value is compared to the average $N_{0}$ value. This is a promising result, as it shows that a single calibration could potentially be used for both sites and all dates collected.

Table 2. Calculated calibration $\left(N_{0}\right)$ values.

\begin{tabular}{ccccc}
\hline & Hygrophilous Grassland (cpm) & Average Error & Pine (cpm) & Average Error \\
\hline Survey one & 131.406 & -2.034 & 133.043 & 0.375 \\
Survey two & 135.475 & 2.034 & 132.293 & -0.375 \\
Average & 133.441 & - & 132.668 & - \\
\hline
\end{tabular}

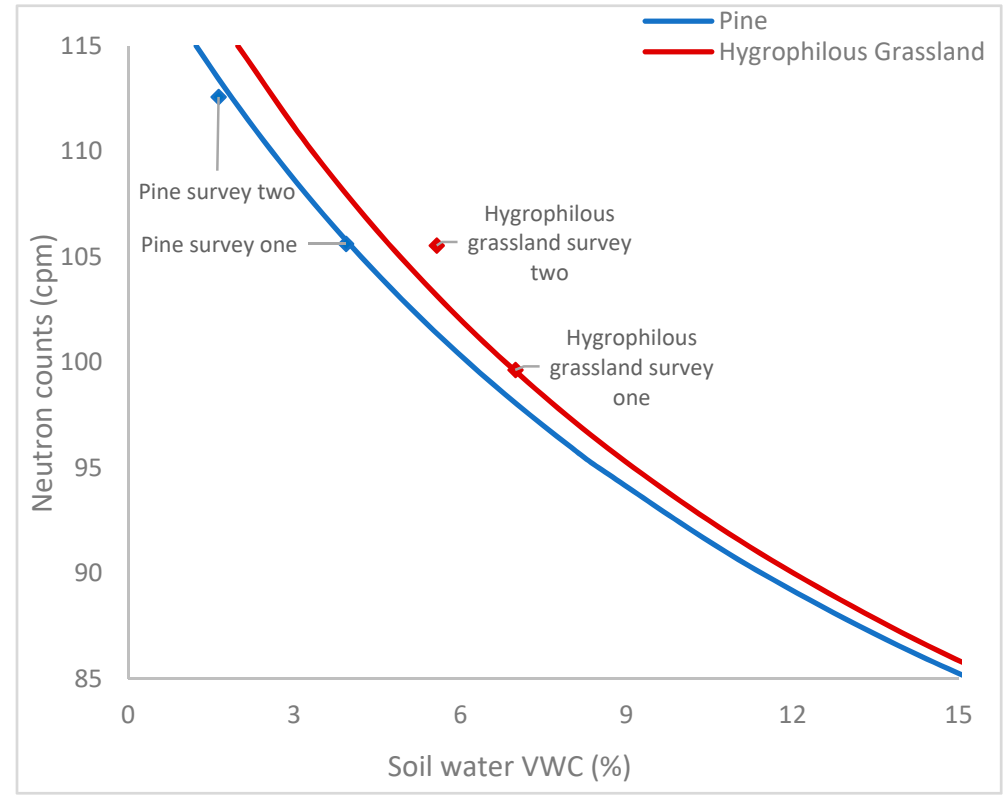

Figure 6. Calibration curve of the hygrophilous grassland and pine sites. 


\subsection{Cosmic Ray Neutron Rover Validation}

The average $N_{0}$ values $133.441 \mathrm{cpm}$ (hygrophilous grassland) and $132.668 \mathrm{cpm}$ (pine) were then used in Equation (6) to determine the CRNR soil water maps for surveys three and four at both sites. The CRNR soil water maps were then validated against the hydro-sense soil water maps for the corresponding surveys. First, general observations on soil water patterns and gradients across the landscape are discussed. Next, a statistical approach is used to validate the CRNR soil water estimates. The generated hydro-sense and CRNR soil water maps for the hygrophilous grassland site are illustrated in Figure 7.

Maps produced using the hydro-sense data exhibited clear soil water patterns of the hygrophilous grassland survey site. The high soil water values in the landscape occur in the landscape depressions, which also coincide with a change in vegetation. There is temporal stability within the site, as the overall soil water patterns are constant and represented in both surveys, even though the locations of the hydro-sense points differ from survey to survey. Overall, the hydro-sense soil water maps differentiated the spatial patterns of soil water across the landscape.

The CRNR provided spatial estimates of soil water that represent the general soil water pattern of the landscape. Although the CRNR discriminates the overall soil water pattern of the area, the soil water gradients are slightly skewed (compared to the hydro-sense soil water gradients) due to the difference in measurement volume between the hydro-sense and the CRNR. The hydro-sense soil water map value range (survey three: 0.74 to 41.98 VWC (\%) and survey four: 1.63 to 50.37 VWC (\%)) is larger than that of the subsequent CRNR soil water value range (survey three: 2.08 to 13.48 VWC (\%) and survey four: 9.59 to $22.37 \mathrm{VWC}(\%)$ ) This is primarily due to the difference in support volumes of the two instruments used to produce the soil water maps.
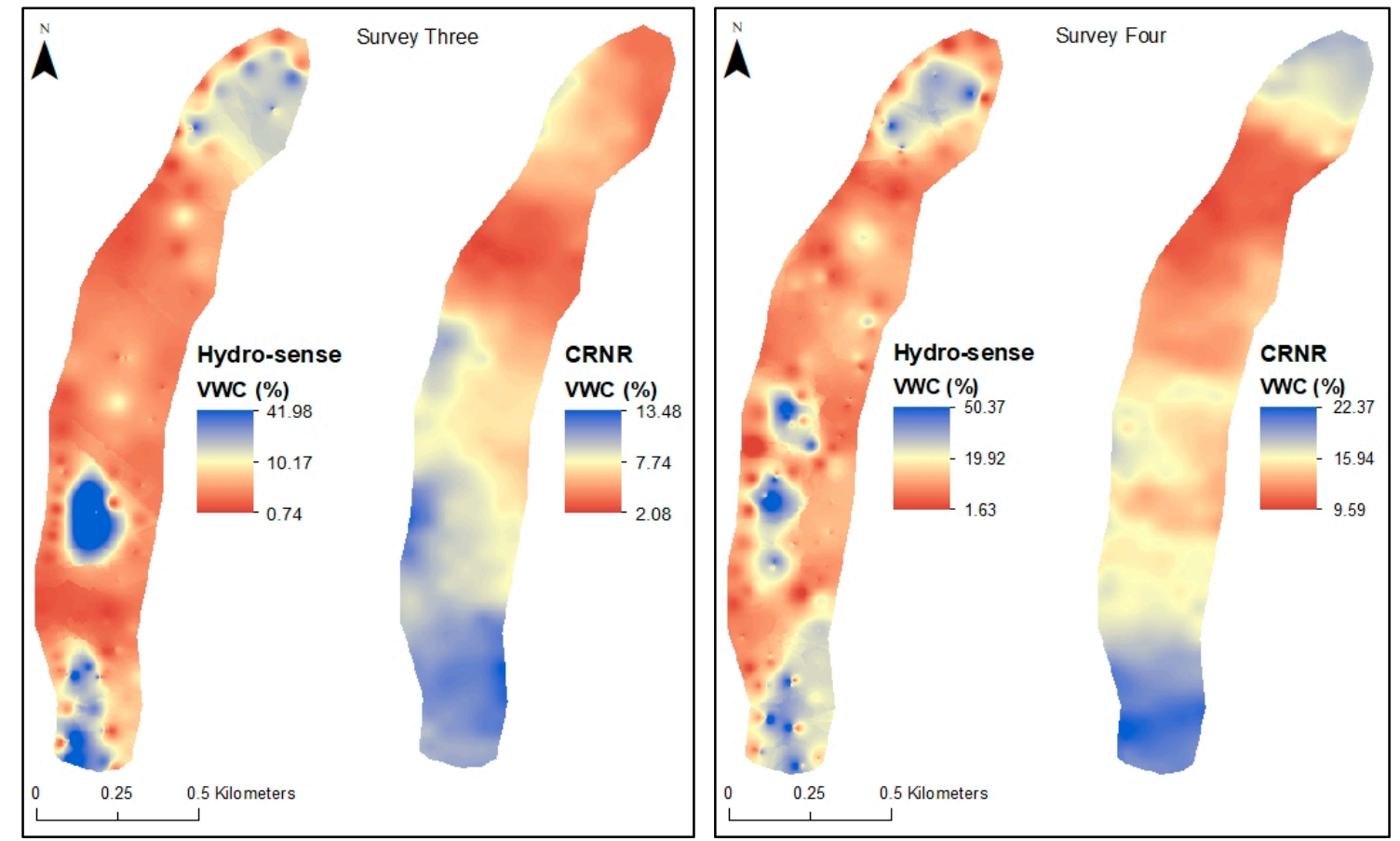

Figure 7. Hygrophilous grassland hydro-sense and CRNR soil water maps.

The landscape peat depressions could not be driven over, without the risk of the vehicle getting stuck and were therefore navigated around (surveying along the border of the depression). Therefore, the high soil water values within the depression zones, which were measured by the hydro-sense (accessible by foot), were not effectively captured by the CRNR, which is due to the CRNR's measurement footprint, as well as, the CRNR not measuring the neutron count directly over the depression zones, which is supported by the research findings by Köhli, et al. [13], which stated that the signal strength 
of cosmic ray neutron technology is non-linear per radial distance and is extraordinarily sensitive to the first few meters of the instrument, resulting in almost half of the neutron intensity arising from the first $50 \mathrm{~m}$ from the instrument.

The generated hydro-sense and CRNR soil water maps for the pine site are illustrated in Figure 8. The maps produced using the hydro-sense data exhibited clear soil water patterns of the pine survey site. The soil water pattern of the hydro-sense surveys was evident in the surveys, such that the change to hygrophilous vegetation, which occurred towards the centre of the site showed the expected increase in soil water indicative of these depressions. This was expected, as the pine trees are better adapted to the drier raised areas in study site where soil water values were relatively low. In addition, the pine trees probably use more water than the hygrophilous vegetation found in these depressions. The temporal soil water stability is also seen, as the general soil water patterns are maintained throughout the two surveys, even though the hydro-sense soil water points were not taken at the same locations within the site for the two surveys. The hydro-sense soil water maps differentiated the spatial patterns of soil water across the landscape.

The CRNR provided spatial estimates of soil water over the site and the soil water patterns were consistent to that of the hydro-sense soil water measurements. There is a difference in the soil water gradients between the hydro-sense and CRNR soil water maps, which is due to the difference in support volume of the two instruments used. The hydro-sense soil water map value range (survey three: 0.33 to 6.92 VWC (\%) and survey four: 4.24 to 18.61 VWC (\%)) is slightly larger than that of the subsequent CRNR soil water value range (survey three: 0.00 to 5.89 VWC (\%) and survey four: 4.91 to $9.15 \mathrm{VWC}(\%))$. This is primarily due to the difference in support volumes of the two instruments used to produce the soil water maps.
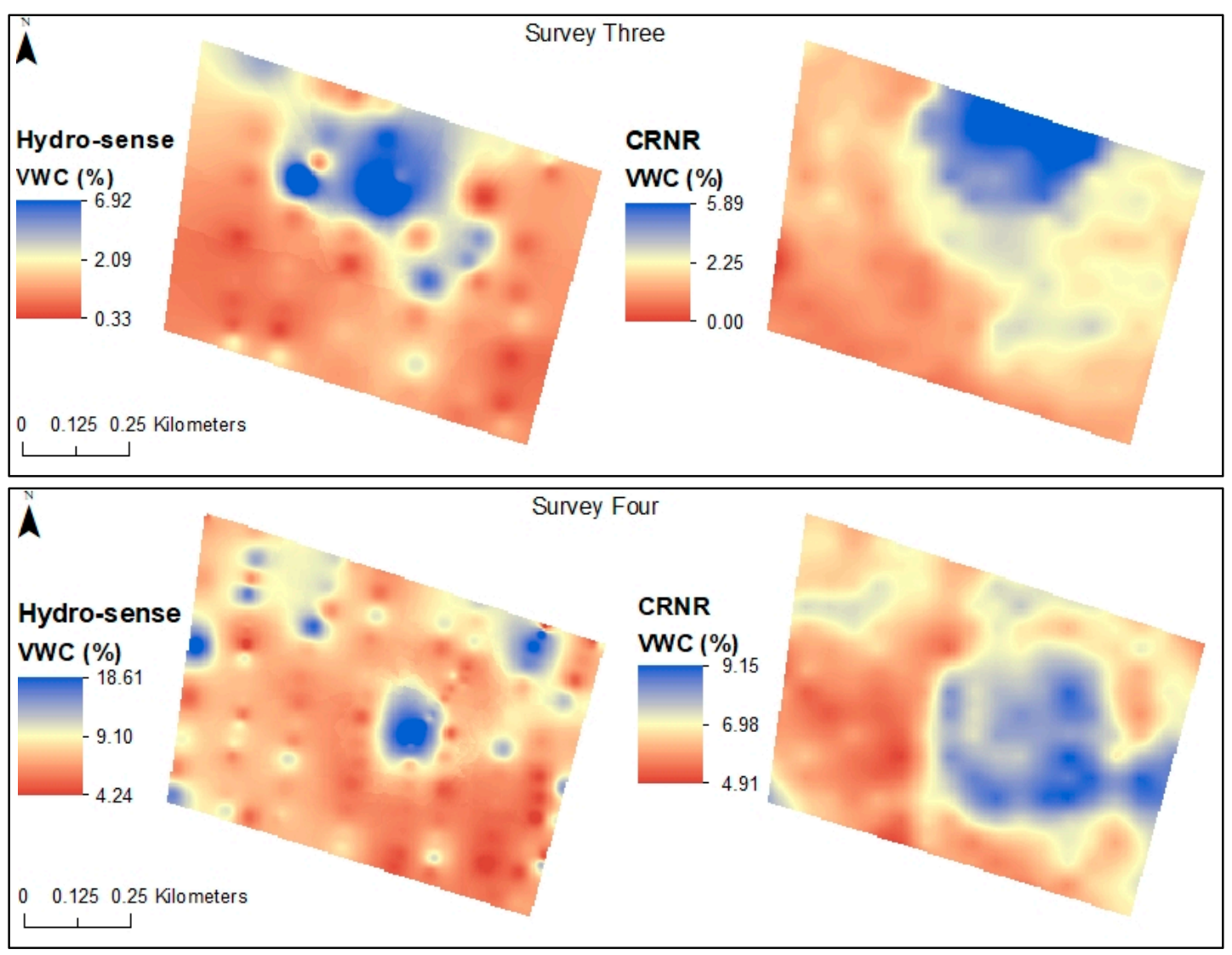

Figure 8. Pine hydro-sense and CRNR soil water maps.

The surveys (three and four) were conducted in different seasons, which explains the difference in soil water ranges between hydro-sense surveys three and four and CRNR surveys three and four. 
Survey three was conducted in the dry season (winter), therefore the soil water values from the hydro-sense and CRNR are lower than that of subsequent survey four values, which was conducted in the wet season (summer).

The range of soil water values of the hydro-sense soil water maps were generally larger than that of the subsequent CRNR soil water range. This occurs as the hydro-sense has a small support volume and is therefore able to pick up maximum and minimum values within the landscape, especially on a small spatial scale. The CRNR has a smaller range of soil water values as it measures area-averaged soil water at an intermediate scale and therefore averages the fluctuations in soil water over the landscape. It is also important to note that more advanced interpolation techniques may reduce the mismatch in soil water ranges of the hydro-sense and CRNR estimates.

Intensive hydro-sense soil water surveys were conducted for the purpose of calibrating and validating the CRNR within a research framework. The CRNR would be calibrated less intensively for real world applications and if larger survey areas were mapped. Thus, the labour and time required to produce representative soil water maps of a survey area would potentially be less than that used in this research study.

The site boundaries of both survey areas are defined as the outer survey path of the CRNR. The CRNR at both sites has a measurement footprint of $\sim 200 \mathrm{~m}$. Therefore, the area $200 \mathrm{~m}$ beyond the border of the site influences the neutron count, when surveying along the border of the site. This could potentially result in differences in soil patterns between the hydro-sense and CRNR soil water maps, as the boundary measurements of the CRNR is affected by the conditions beyond the survey site, whilst the hydro-sense soil water map is an interpolation of the various sample points within the survey site.

The hygrophilous grassland survey area is narrow in width $(\sim 300 \mathrm{~m})$ and is smaller than the diameter of the CRNR's measurement footprint. Therefore, the CRNR would not be able to adequately differentiate the east-to-west soil water gradients of the survey area. This is further highlighted by the large changes in the soil water content over relatively small distances, within the hygrophilous grassland survey area.

The average VWC (\%) from the hydro-sense and corresponding CRNR soil water maps were obtained and plotted, with the 1:1 line (dashed) Figure 9. The graph shows that the average value of the CRNR soil water maps correlate well with that of the average value of the hydro-sense soil water maps and have an $R^{2}$ value of 0.993 . This shows that the calibration procedure carried out was adequate and that the calibration values are valid over different seasons, as survey three was conducted in the dry season and survey four was conducted in the wet season.

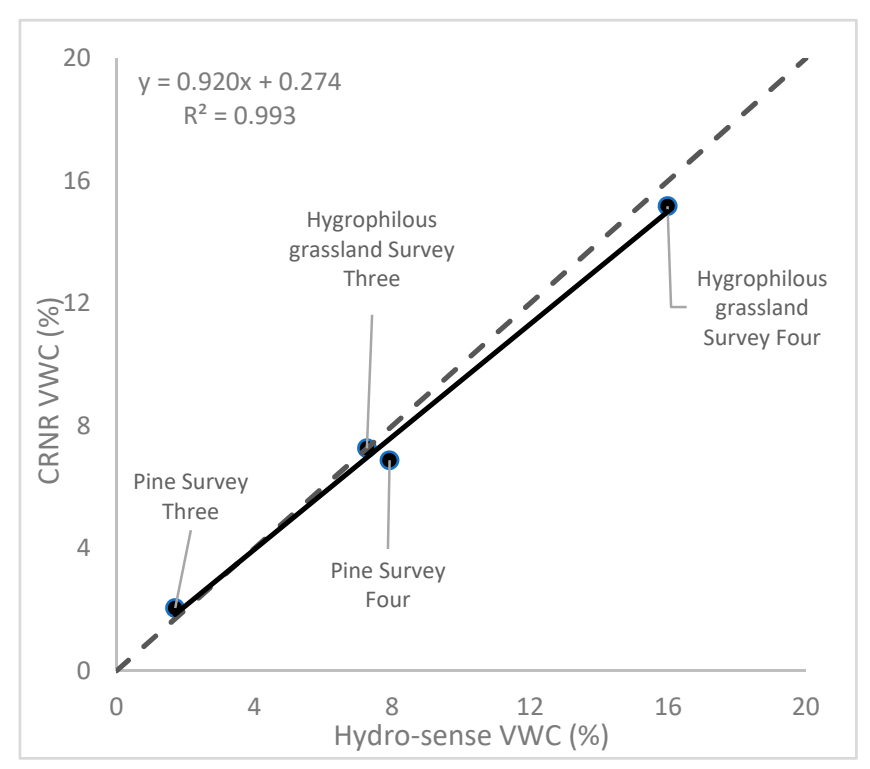

Figure 9. Average hydro-sense and CRNR VWC (\%) survey values. 
To further assess the capability of the CRNR to provide spatial estimates of soil water, the spatial soil water values of the hydro-sense and CRNR were compared. This was carried out by creating a spatial grid (fishnet), at a pre-defined resolution, and using this spatial grid to obtain pixel values from both the hydro-sense and CRNR soil water maps across the survey landscape (an example of the fishnet grid, at the pine site is illustrated in (Figure 10)).

For the purpose of this research, a $25 \mathrm{~m}$ grid size was chosen, according to the survey site sizes and the overall spatial characteristics of the soil water maps. The grid was overlaid onto the hydro-sense and CRNR soil water maps (which have identical spatial extents), and the pixel values were obtained. The pairs of pixel values obtained for each survey were then assessed.

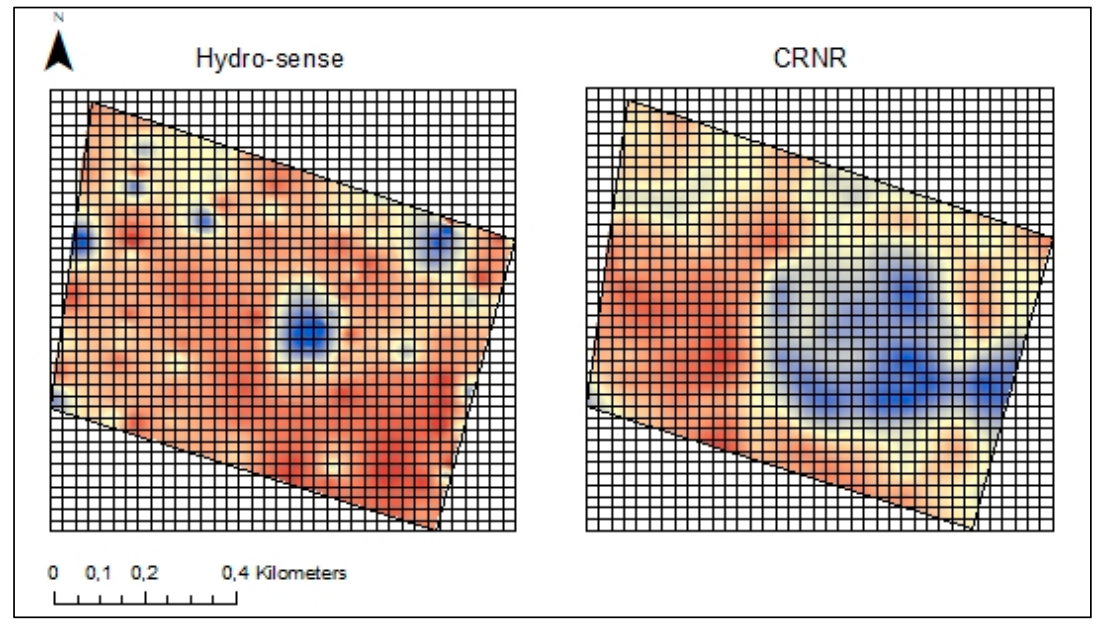

Figure 10. Illustration of the fishnet grid on the Pine (survey four) hydro-sense and CRNR maps.

First, the descriptive statistics were determined for each dataset. From Table 3, the hydro-sense and corresponding CRNR survey mean values are similar. The range, standard error, kurtosis, skewness and standard deviation of the hydro-sense values are generally larger than the corresponding CRNR values.

Table 3. Descriptive statistics of the hydro-sense and CRNR soil water maps.

\begin{tabular}{ccccc}
\hline \multicolumn{5}{c}{ Hygrophilous grassland } \\
\hline Survey & \multicolumn{2}{c}{ Three } & \multicolumn{2}{c}{ Four } \\
\hline Dataset & Hydro-sense & CRNR & Hydro-sense & CRNR \\
\hline Mean & 7.369 & 7.232 & 16.220 & 15.103 \\
Standard Error & 0.162 & 0.087 & 0.195 & 0.091 \\
Standard Deviation & 5.038 & 2.697 & 6.073 & 2.828 \\
Kurtosis & 4.529 & -1.016 & 0.315 & -0.292 \\
Skewness & 1.873 & 0.081 & 0.804 & 0.338 \\
Range & 30.792 & 10.547 & 38.407 & 12.439 \\
Minimum & 1.407 & 2.303 & 3.020 & 9.825 \\
Maximum & 32.198 & 12.850 & 41.426 & 22.263 \\
\hline \multicolumn{5}{c}{ Pine } \\
\hline Survey & \multicolumn{5}{c}{} \\
\hline Dataset & Thdro-sense & CRNR & Hydro-sense & CRNR \\
\hline Mean & 1.713 & 2.069 & 7.905 & 6.888 \\
Standard Error & 0.030 & 0.040 & 0.052 & 0.031 \\
Standard Deviation & 0.882 & 1.167 & 1.510 & 0.891 \\
Kurtosis & 2.444 & 1.060 & 2.932 & -0.654 \\
Skewness & 1.462 & 1.139 & 1.288 & 0.316 \\
Range & 5.750 & 5.788 & 10.529 & 3.912 \\
Minimum & 0.445 & 0.000 & 4.848 & 5.085 \\
Maximum & 6.195 & 5.788 & 15.377 & 8.997 \\
\hline
\end{tabular}


Scattergraphs of the hydro-sense ( $x$-axis) against the CRNR soil water values (both extracted using the $25 \mathrm{~m}$ grid) were plotted for both the hygrophilous grassland and pine site Figure 11 . The data from surveys three (red) and four (blue) were combined in each graph to cover a larger range of CRNR soil water values, as survey three was conducted in the dry season (winter) and survey four was conducted in the wet season (summer). The pine site has a higher $\mathrm{R}^{2}(0.793)$ between the hydro-sense and CRNR than the hygrophilous grassland (0.439).
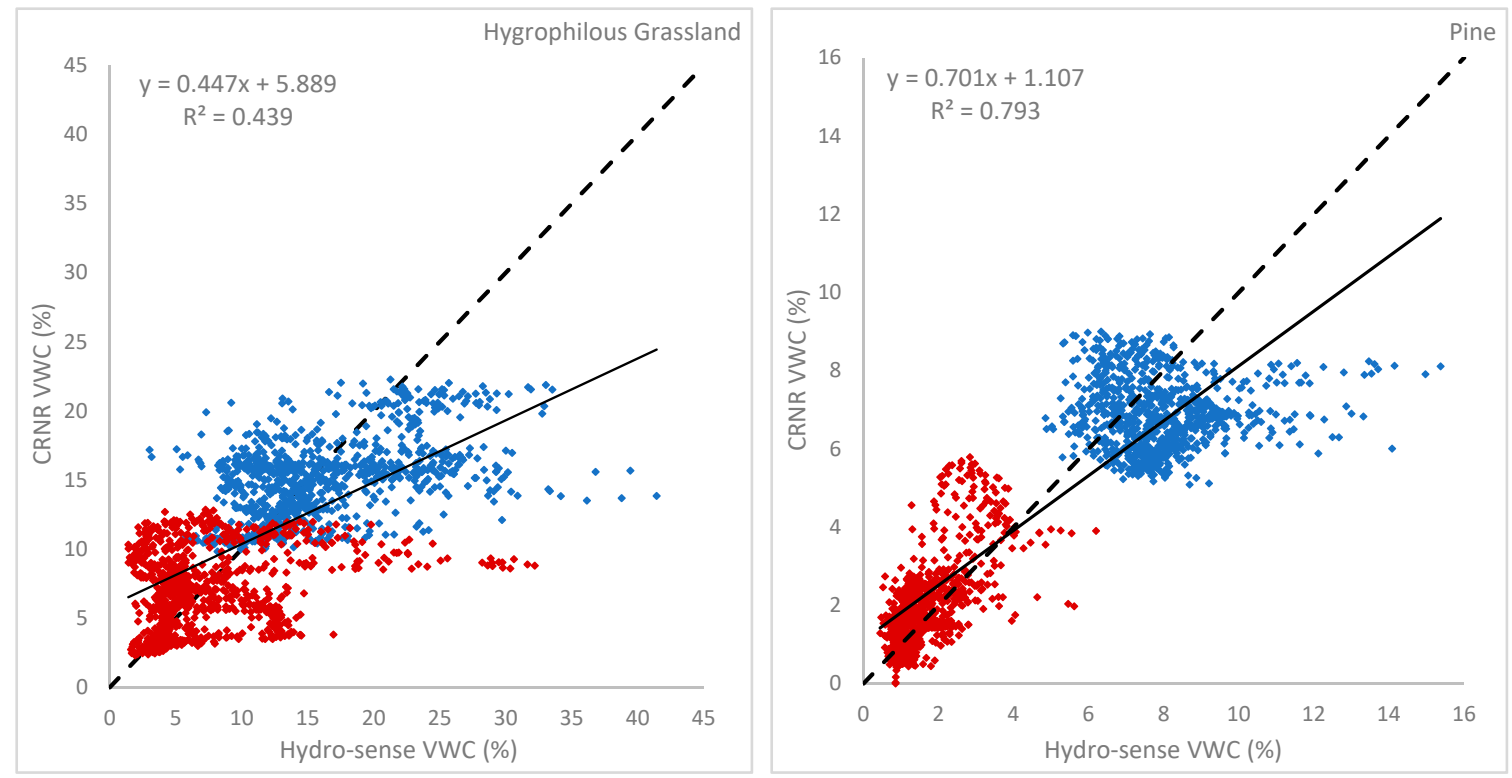

Figure 11. Scatterplot of hydro-sense ( $x$-axis) and CRNR (y-axis).

The performance metrics were determined for each survey (Table 4). With regards to the hygrophilous grassland surveys, the unbiased Root Mean Squared Error (ubRMSE) [37] ranges from 5.220 (Survey three) to 5.400 VWC (\%) (Survey four). With regards to the pine surveys, the ubRMSE ranges from 0.910 (Survey three) to 1.832 VWC (\%) (Survey four). The pine surveys have a lower ubRMSE compared to the hygrophilous grassland surveys.

Table 4. Survey performance metrics.

\begin{tabular}{ccccccc}
\hline & \multicolumn{3}{c}{ Hygrophilous Grassland } & \multicolumn{3}{c}{ Pine } \\
\hline Performance Metric & RMSE & Bias & ubRMSE & RMSE & Bias & ubRMSE \\
\hline Survey Three & 5.221 & -0.137 & 5.220 & 0.961 & 0.308 & 0.910 \\
Survey Four & 5.514 & -1.118 & 5.400 & 2.032 & -0.880 & 1.832 \\
\hline
\end{tabular}

From the validation of the CRNR with hydro-sense soil water data, it is apparent that the CRNR can provide spatial estimates of soil water, which correlate well with the hydro-sense data. There are a few issues that have become apparent in this study. Firstly, a limitation of this study is that the soil water measurements from the $0-20 \mathrm{~cm}$ depth (hydro-sense) are used to calibrate the CRNR. It is worth noting again that the calibration used in this study may not hold for times without a hydrostatic profile. Therefore, the revised calibration approach, which uses a horizontal and depth weighting scheme is recommended, as it has been shown to improve the neutron to soil water estimates in these instances and would result in a decrease in the ubRMSE. Moreover, the low altitude of the site, as well as the number of neutron tubes (six) that this particular CRNR possesses, results in relatively low neutron counts within the one-minute interval, which results in a decrease in the instruments precision. This could be overcome by using a CRNR that consists of more neutron tubes; however, this is a financial limitation. 
The shape of the hygrophilous grassland survey area does not allow for the CRNR to have enough distance to spatially measure the variability of soil water, as the survey area is too narrow. The long and narrow shape of the catchment also results in a large proportion of measurements being obtained on the border of the survey area, which is an issue, as the measurements along the border are affected by the area beyond the survey area that are not accounted for.

The large change in soil water over small spatial scales occurred in the hygrophilous grassland survey area, which was picked up by the hydro-sense measurements, but not adequately represented by the CRNR due to the footprint scale of the CRNR. The hygrophilous grassland had several depressions, which exhibited high soil water values in relation to the surrounding raised areas. These depressions were navigated around, to avoid the vehicle getting stuck. The CRNR is most sensitive to the area nearest to the sensor, therefore navigating around the depression does not adequately obtain the count rate that driving directly over the depression would.

The direction and speed at which a soil water gradient is approached affects the output CRNR map. When surveying, the neutron counts are recorded at one-minute intervals. When surveying across a soil water gradient, for example moving from a high soil water content to a low soil water content, the location at which the recorded value is noted, results in a bias, as the wet soil water value could be recorded beyond the wet boundary. This is highly possible as the transitions/gradients in soil water are not linear.

\section{Conclusions and Recommendations}

Soil water is an important hydrological variable that varies both spatially and temporally. It is therefore a dynamic resource and knowledge of soil water at a range of scales is important for several applications that extend through numerous disciplines. The CRNR is an innovative tool to map surface soil water. Once calibrated, the CRNR provides spatial estimates of soil water at a hectometre scale. The calibration procedure carried out in this study was intensive, as there is currently no standardized approach of obtaining a representative soil water calibration dataset. The assessment of the calibrations resulted in very similar calibration values $\left(N_{0}\right)$ for all calibrated surveys.

The validation of the CRNR soil water estimates provided a promising outlook on the potential applications of the method, as the CRNR provided reliable soil water maps over both survey sites, as it was able to adequately represent the soil water patterns and identify the soil water gradients throughout the landscape. The results of the study provide evidence that the CRNR is a valuable tool for producing soil water estimates at an intermediate scale. This is promising, as it creates intriguing new possibilities to advance scientific knowledge of the spatial variability of soil water and the impact it has on agriculture, hydrology, ecology and meteorology. The validation of the CRNR also showed that the CRNR is most sensitive to the area nearest to the instrument.

The CRNR and hydro-sense soil water maps correlate better at the pine site. Forest sites are deemed to be challenging for cosmic ray technology due to the sources and variations of hydrogen within a forest. The higher correlation could be due to the smaller range of soil water values at the pine site, less variability in the soil water content over small spatial scales and the vehicle being able to move throughout the pine survey area. The pine site was also more favourable in terms of the survey area shape, as it was sufficiently wide in comparison to the hygrophilous grassland site.

Although the CRNR used in this research study provided adequate results, there is always room for improvement. From the study, a few lessons have been learnt, which could assist future studies using the CRNR. In order to improve on the accuracy of the CRNR, larger and/or more neutron detectors would result in an increase in the neutron count per interval, which would improve the precision of the instrument and would improve the application of the CRNR. The use of cadmium shielding could also be used in future research, to cover the CRNR from neutrons beyond the boundary of the survey area, when surveying along the boundary of the survey site. The choice of survey areas is also important, as the CRNR has a large ( $200 \mathrm{~m}$ radius) measurement footprint. Future studies should incorporate the revised weighted calibration data approach (if resources and labour permit 
it). The revised calibration approach is more robust in comparison to the conventional approach and subsequently improves the performance of the cosmic ray neutron method by increasing the overall accuracy. It is important to select a survey shape that is not too narrow, and the size of the survey area should also be sufficiently large for the majority of the CRNR measurements to be taken within the site in comparison to along the site border. Survey sites that restrict the CRNR from navigating throughout the site should not be considered, particularly in cases where the avoided areas exhibit a great change in soil water in relation to the surrounding areas. A buffer area could be implemented in future CRNR surveys, so that the border on the survey is 50-100 m away from the survey path. From the previous studies, it is apparent that the cosmic ray neutron instruments (CRNR and CRNS) are more sensitive to the area nearest to the instrument and that the sensitivity decreases with distance from the instrument. This would affect the calibration and validation of the CRNR, if areas are navigated around by vehicle, but surveyed in the calibration and validation dataset by foot. Alternatively, all areas that are not accessible by vehicle should be avoided when obtaining a representative soil water map, as this would result in point values that are highly representative in the landscape but less representative by the CRNR's measurements. This issue becomes more apparent if the area that is not accessible by vehicle exhibits a great difference in soil water content over small spatial scales than the areas that are surveyed over.

Supplementary Materials: The following is available online at http://www.mdpi.com/2306-5338/6/3/65/s1, Excel document containing the Cosmic Ray Neutron Rover (raw) data and the Hydro-sense soil water data for Surveys one, two, three and four, at the hygrophilous grassland and pine forest site.

Author Contributions: Conceptualization: T.V., C.E. and T.E.F.; methodology, T.V., C.E. and T.E.F.; software, T.E.F.; validation, T.V.; formal analysis, T.V.; investigation, T.V.; resources, T.V., C.E. and T.E.F.; data curation, T.V.; writing —original draft preparation, T.V.; writing—review and editing, C.E. and T.E.F; supervision, C.E. and T.E.F.; project administration, C.E.; funding acquisition, C.E. and T.E.F.

Funding: The authors gratefully acknowledge funding from the Partnerships for Enhanced Engagement in Research (USA); South African Agency for Science and Technology Advancement; United States Agency for International Development; University of KwaZulu-Natal; University of Pretoria; the National Research Foundation (NRF) of South Africa; the Department of Science and Technology (South African), the Water Research Commission (WRC) and the South African Environmental Observation Network (SAEON). T.E.F. acknowledges the financial support of The Daugherty Water Food Global Institute, the Global Engagement office of the University of Nebraska-Lincoln and the USDA National Institute of Food and Agriculture, Hatch project \#1009760.

Conflicts of Interest: The authors declare no conflict of interest.

\section{References}

1. Zreda, M. Land-surface hydrology with cosmic-ray neutrons: Principles and applications. J. Jpn. Soc. Soil Phys. 2016, 132, 25-30.

2. Baatz, R.; Bogena, H.R.; Franssen, J.H.; Huisman, J.A.; Montzka, C.; Vereecken, H. An empirical vegetation correction for soil water content quantification using cosmic ray probes. Water Resour. Res. 2015, 51, 2030-2046. [CrossRef]

3. Ochsner, T.E.; Cosh, M.H.; Cuenca, R.H.; Dorigo, W.A.; Draper, C.S.; Hagimoto, Y.; Kerr, Y.H.; Larson, K.M.; Njoku, E.G.; Small, E.E.; et al. State of the art in large-scale soil moisture monitoring. Soil Sci. Soc. Am. J. 2013, 77, 1888-1919. [CrossRef]

4. Stocker, B.D.; Zscheischler, J.; Keenan, T.F.; Prentice, I.C.; Seneviratne, S.I.; Peñuelas, J. Drought impacts on terrestrial primary production underestimated by satellite monitoring. Nat. Geosci. 2019. [CrossRef]

5. McJannet, D.; Hawdon, A.; Baker, B.; Renzullo, L.; Searle, R. Multiscale soil moisture estimates using static and roving cosmic-ray soil moisture sensors. Hydrol. Earth Syst. Sci. 2017, 21, 6049-6067. [CrossRef]

6. Walker, J.P.; Dumedah, G.; Monerris, A.; Gao, Y.; Rudiger, C.; Wu, X.; Panciera, R.; Merlin, O.; Pipunic, R.; Ryu, D.; et al. High Resolution Soil Moisture Mapping. In Digital Soil Assessments and Beyond, Proceedings of the Fifth Global Workshop on Digital Soil Mapping, Sydney, Australia, 10-13 April 2012; CRC Press: Boca Raton, FL, USA, 2012; pp. 45-51. 
7. Rosolem, R.; Hoar, T.; Arellano, A.; Anderson, J.L.; Shuttleworth, W.J.; Zeng, X.; Franz, T.E. Translating aboveground cosmic-ray neutron intensity to high-frequency soil moisture profiles at sub-kilometer scale. Hydrol. Earth Syst. Sci. 2014, 18, 4363-4379. [CrossRef]

8. McCabe, M.F.; Rodell, M.; Alsdorf, D.E.; Miralles, D.G.; Uijlenhoet, R.; Wagner, W.; Lucieer, A.; Houborg, R.; Verhoest, N.E.C.; Franz, T.E.; et al. The future of Earth observation in hydrology. Hydrol. Earth Syst. Sci. 2017, 21, 3879-3914. [CrossRef]

9. Zreda, M.; Shuttleworth, W.J.; Zeng, X.; Zweck, C.; Desilets, D.; Franz, T.; Rosolem, R. COSMOS: The COsmic-ray Soil Moisture Observing System. Hydrol. Earth Syst. Sci. 2012, 16, 4079-4099. [CrossRef]

10. Franz, T.E.; Zreda, M.; Rosolem, R.; Ferre, T.P.A. Field Validation of a cosmic-ray neutron sensor using a distributed sensor network. Vadose Zone J. 2012, 11. [CrossRef]

11. Zreda, M.; Desilets, D.; Ferre, T.P.A.; Scott, R.L. Measuring soil moisture content non-invasively at intermediate spatial scale using cosmic-ray neutrons. Geophys. Res. 2008, 35. [CrossRef]

12. Dong, J.; Ochsner, T.E.; Zreda, M.; Cosh, M.H.; Zou, C.B. Calibration and Validation of the COSMOS Rover for Surface Soil Moisture Measurement. Vadose Zone J. 2014, 13. [CrossRef]

13. Köhli, M.; Schrön, M.; Zreda, M.; Schmidt, U.; Dietrich, P.; Zacharias, S. Footprint characteristics revised for field-scale soil moisture monitoring with cosmic-ray neutrons. Water Resour. Res. 2015, 10, 5772-5790. [CrossRef]

14. Desilets, D.; Zreda, M.; Ferre, T.P.A. Nature's neutron probe: Land surface hydrology at an elusive scale with cosmic rays. Water Resour. Res. 2010, 46,1-7. [CrossRef]

15. Chrisman, B.; Zreda, M. Quantifying mesoscale soil moisture with the cosmic-ray rover. Hydrol. Earth Syst. Sci. 2013, 17, 5097-5108. [CrossRef]

16. Franz, T.E.; Wang, T.; Avery, W.; Finkenbiner, C.; Brocca, L. Combined analysis of soil moisture measurements from roving and fixed cosmic ray neutron probes for multiscale real-time monitoring. Geophys. Res. Lett. 2015, 42, 3389-3396. [CrossRef]

17. Schrön, M.; Rosolem, R.; Köhli, M.; Piussi, L.; Schroter, I.; Iwema, J.; Kogler, S.; Oswald, S.E.; Wollschlager, U.; Dietrich, P.; et al. The Cosmic-Ray Neutron Rover-Mobile Surveys of Field Soil Moisture and the Influence of Roads. Water Resour. Res. 2018, 54, 6441-6459. [CrossRef]

18. Fersch, B.; Jagdhuber, T.; Schrön, M.; Volksch, I.; Jager, M. Synergies for soil moisture retrieval across scales from airborne polarimetric SAR, cosmic ray neutron roving, and an in situ sensor network. Water Resour. Res. 2018, 54. [CrossRef]

19. Finkenbiner, C.E.; Franz, T.E.; Gibson, J.; Heeren, D.M.; Luck, J. Integration of hydrogeophysical datasets and empirical orthogonal functions for improved irrigation water management. Precis. Agric. 2019, 20, 78-100. [CrossRef]

20. Gibson, J.; Franz, T.E. Spatial prediction of near surface soil water retention functions using hydrogeophysics and empirical orthogonal functions. J. Hydrol. 2018, 561, 372-383. [CrossRef]

21. Grundling, A.T.; van den Berg, E.C.; Price, J.S. Assessing the distribution of wetlands over wet and dry periods and land-use change on the Maputaland Coastal Plain, north-eastern KwaZulu-Natal, South Africa. S. Afr. J. Geomat. 2013, 2, 120-138.

22. Zhu, X.; Shao, M.; Zeng, C.; Jia, X.; Huang, L.; Zhang, Y.; Zhu, J. Application of cosmic-ray neutron sensing to monitor soil water content in an alpine meadow ecosystem on the northern Tibetan Plateau. J. Hydrol. 2016, 536, 247-254. [CrossRef]

23. Shuttleworth, W.J.; Zreda, M.; Zeng, X.; Zweck, C.; Ferre, T.P.A. The COsmic-ray Soil Moisture Observing System (COSMOS): A non-invasive, intermediate scale soil moisture measurement network. British. Hydrol. Soc. 2010, 12, 14551.

24. Mcjannet, D.; Franz, T.; Hawdon, A.; Boadle, D.; Baker, B.; Almeida, A.; Silberstein, R.; Lambert, T.; Desilets, D. Field testing of the universal calibration function for determination of soil moisture with cosmic-ray neutrons. Water Resour. Res. 2014, 50. [CrossRef]

25. Franz, T.E.; Zreda, M.; Ferre, T.P.A.; Rosolem, R. An assessment of the effect of horizontal soil moisture heterogeneity on the area-average measurement of cosmic-ray neutrons. Water Resour. Res. 2013, 49, 1-9. [CrossRef]

26. Schrön, M.; Köhli, M.; Scheiffele, L.; Iwema, J.; Bogena, H.R.; Lv, L.; Martini, E.; Baroni, G.; Rosolem, R.; Weimar, J.; et al. Improving Calibration and Validation of Cosmic-Ray Neutron Sensors in the Light of Spatial Sensitivity-Theory and Evidence. Hydrol. Earth Syst. Sci 2017. [CrossRef] 
27. Desilets, D.; Zreda, M. Footprint diameter for a cosmic-ray soil moisture probe: Theory and Monte Carlo simulations. Water Resour. Res. 2013, 49, 3566-3575. [CrossRef]

28. Desilets, D. Radius of Influence for a Cosmic-Ray Soil Moisture Probe: Theory and Monte Carlo Simulations; Sandia National Laboratories: Livermore, CA, USA, 2011.

29. Franz, T.E.; Zreda, M.; Ferre, T.P.A.; Rosolem, R.; Zweck, C.; Stillman, S.; Zeng, X.; Shuttleworth, W.J. Measurement depth of the cosmic ray soil moisture probe affected by hydrogen from various sources. Water Resour. Res. 2012, 48. [CrossRef]

30. Andreasen, M.; Jensen, K.H.; Desilets, D.; Franz, T.E.; Zreda, M.; Bogena, H.R.; Looms, M.C. Status and Perspectives on the Cosmic-Ray Neutron Method for Soil Moisture Estimation and Other Environmental Science Applications. Vadose Zone J. 2017, 16. [CrossRef]

31. Montzka, C.; Bogena, H.R.; Zreda, M.; Monerris, A.; Morrison, R.; Muddu, S.; Vereecken, H. Validation of Spaceborne and Modelled Surface Soil Moisture Products with Cosmic-Ray Neutron Probes. Remote Sens. 2017, 9, 103. [CrossRef]

32. Vather, T.; Everson, C.S.; Mengistu, M.G.; Franz, T.E. Cosmic ray neutrons provide innovative technique for estimating intermediate scale soil moisture. S. Afr. J. Sci. 2018, 114, 79-87. [CrossRef]

33. Baroni, G.; Oswald, S.E. A scaling approach for the assessment of biomass changes and rainfall interception using Cosmic-Ray neutron sensing. J. Hydrol. 2015, 525, 264-276. [CrossRef]

34. Rosolem, R.; Shuttleworth, W.J.; Zreda, M.; Franz, T.E.; Zeng, X.; Kurc, S.A. The Effect of Atmospheric Water Vapor on Neutron Count in the Cosmic-Ray Soil Moisture Observing System. J. Hydrometeorol. 2013, 2013, 1659-1671. [CrossRef]

35. Hawdon, A.; Mcjannet, D.; Wallace, J. Calibration and correction procedures for cosmic-ray neutron soil moisture probes located across Australia. Water Resour. Res. 2014, 50, 5029-5043. [CrossRef]

36. Avery, W.A.; Finkenbiner, C.; Franz, T.E.; Wang, T.; Nguy-Robertson, A.L.; Suyker, A.; Arkebauer, T.; Munoz-Arriola, F. Incorporation of globally available datasets into the roving cosmic-ray neutron probe method for estimating field-scale soil water content. Hydrol. Earth Syst. Sci. 2016, 20, 3859-3872. [CrossRef]

37. Babaeian, E.; Sadeghi, M.; Franz, T.E.; Jones, S.; Tuller, M. Mapping soil moisture with the OPtical TRApezoid Model (OPTRAM) based on long-term MODIS observations. Remote Sens. Environ. 2018, 211, 425-440. [CrossRef]

(C) 2019 by the authors. Licensee MDPI, Basel, Switzerland. This article is an open access article distributed under the terms and conditions of the Creative Commons Attribution (CC BY) license (http://creativecommons.org/licenses/by/4.0/). 